\title{
Antiepileptic drugs in critically ill patients
}

\author{
Salia Farrokh ${ }^{1 *}$ (D, Pouya Tahsili-Fahadan ${ }^{2,4}$, Eva K. Ritzl ${ }^{2,3}$, John J. Lewin $\mid I^{1}$ and Marek A. Mirski ${ }^{1}$
}

\begin{abstract}
Background: The incidence of seizures in intensive care units ranges from 3.3\% to 34\%. It is therefore often necessary to initiate or continue anticonvulsant drugs in this setting. When a new anticonvulsant is initiated, drug factors, such as onset of action and side effects, and patient factors, such as age, renal, and hepatic function, should be taken into account. It is important to note that the altered physiology of critically ill patients as well as pharmacological and nonpharmacological interventions such as renal replacement therapy, extracorporeal membrane oxygenation, and target temperature management may lead to therapeutic failure or toxicity. This may be even more challenging with the availability of newer antiepileptics where the evidence for their use in critically ill patients is limited.

Main body: This article reviews the pharmacokinetics and pharmacodynamics of antiepileptics as well as application of these principles when dosing antiepileptics and monitoring serum levels in critically ill patients. The selection of the most appropriate anticonvulsant to treat seizure and status epileptics as well as the prophylactic use of these agents in this setting are also discussed. Drug-drug interactions and the effect of nonpharmacological interventions such as renal replacement therapy, plasma exchange, and extracorporeal membrane oxygenation on anticonvulsant removal are also included.

Conclusion: Optimal management of antiepileptic drugs in the intensive care unit is challenging given altered physiology, polypharmacy, and nonpharmacological interventions, and requires a multidisciplinary approach where appropriate and timely assessment, diagnosis, treatment, and monitoring plans are in place.
\end{abstract}

Keywords: Seizure, Antiepileptic drugs, Critical care, Drug-drug Interaction, Pharmacokinetics, Pharmacodynamics

\section{Background}

The incidence of seizures in general intensive care units (ICUs) ranges from $3.3 \%$ to $34 \%$ [1]. Risk factors include common diagnoses such as brain tumor, head trauma, stroke, history of seizure, electrolyte abnormalities, hypoglycemia, infections, and drug overdose or withdrawal [2]. Thus, ICU management of antiepileptic drugs (AEDs) is routinely practiced by intensive care providers.

Selection of the most effective AED with the least adverse events, however, can often be challenging. About a third of patients with seizures fail on monotherapy, necessitating two or more AEDs [3]. Several factors commonly seen in the critical care setting, such as polypharmacy, unpredictable medication pharmacokinetics, and implementation of a variety of nonpharmacological interventions, may lead to drug-drug interactions, elevated risk for drug

\footnotetext{
* Correspondence: sfarrok1@jhmi.edu

${ }^{1}$ Department of Pharmacy, The Johns Hopkins Hospital, 600 N. Wolfe Street, Carnegie 180, Baltimore, MD 21287, USA

Full list of author information is available at the end of the article
}

toxicity, and subtherapeutic drug serum levels; these are discussed in this review.

\section{Pharmacodynamics and pharmacokinetics of AEDs Pharmacodynamics}

AEDs depress abnormal neuronal firing by various mechanisms of action including altering ion channel activity, enhancing gamma-aminobutyric acid (GABA)-mediated inhibition, or reducing glutamate-mediated excitation. While some AEDs have a single mechanism of action, others have multiple mechanisms of action and, in some, the exact mechanism of action is not yet known (Table 1).

When using multiple AEDs, it is reasonable to select medications with different mechanisms of action.

\section{Pharmacokinetics (absorption, distribution, metabolism, excretion)}

Alterations in normal physiology and the physical properties of medications can affect the rate and extent of enteral absorption of medications in the ICU, leading to a need for parenteral administration. Deranged gastrointestinal 
Table 1 Mechanism of action of antiepileptic drugs [113]

\begin{tabular}{|c|c|}
\hline Antiepileptic drug agent & Presumed mechanism of action \\
\hline Brivaracetam & SV2A modulation \\
\hline Carbamazepine & $\mathrm{Na}^{+}$channel blockade \\
\hline Clobazam & GABA potentiation \\
\hline Clonazapam & GABA potentiation \\
\hline Diazepam & GABA potentiation \\
\hline $\begin{array}{l}\text { Fosphenytoin/ } \\
\text { phenytoin }\end{array}$ & $\mathrm{Na}^{+}$channel blockade \\
\hline Lacosamide & $\begin{array}{l}\text { Enhanced slow inactivation of voltage-gated } \\
\mathrm{Na}^{+} \text {channels }\end{array}$ \\
\hline Lamotrigine & $\mathrm{Na}^{+}$channel blockade \\
\hline Levetiracetam & SV2A modulation \\
\hline Lorazepam & GABA potentiation \\
\hline Midazolam & GABA potentiation \\
\hline Oxcarbazepine & $\mathrm{Na}^{+}$channel blockade \\
\hline Pentobarbital & GABA potentiation \\
\hline Perampanel & AMPA glutamate receptor antagonist \\
\hline Phenobarbital & GABA potentiation \\
\hline Topiramate & $\begin{array}{l}\mathrm{Na}^{+} \text {channel blockade, GABA potentiation, } \\
\text { AMPA/Kainate glutamate antagonist }\end{array}$ \\
\hline Valproic acid & $\begin{array}{l}\text { GABA potentiation, glutamate (NMDA) } \\
\text { inhibition, sodium channel and T-type calcium } \\
\text { channel blockade }\end{array}$ \\
\hline Zonisamide & $\mathrm{Na}^{+}$and $\mathrm{Ca}^{2+}$ channel blockade \\
\hline
\end{tabular}

$A M P A$, alpha-amino-3-hydroxy-5-methyl-4-isoxazolepropionic acid, GABA gamma-aminobutyric acid, NMDA, $N$-methyl-D-aspartate, SV2A synaptic vesicle glycoprotein $2 \mathrm{~A}$

absorption may be expected in circumstances of decreased blood flow, intestinal atrophy, dysmotility, and interactions with enteral nutrition. Pharmacokinetic parameters of selected AEDs, including their oral bioavailability, are summarized in Table 2.

Changes in serum $\mathrm{pH}$ as well as both respiratory and renal failure affect the ionized state of many drugs, affecting their penetration across lipophilic-based membranes such as the blood-brain barrier. Bioavailability of active drugs is also affected by alterations in volume of distribution for hydrophilic medications, while hypoalbuminemia increases the unbound (free) fraction of highly albumin-bound medications.

Although drugs are commonly metabolized to less active compounds, prodrugs such as oxcarbazepine and fosphenytoin must be metabolized into their active forms carbamazepine and phenytoin, respectively. Drug metabolism generally occurs in two phases. Phase I involves nonsynthetic reactions to form a modified group. A cytochrome P450 (CYP450) enzyme is frequently involved in such oxidative reactions. Phase II involves synthetic reactions to conjugate the metabolite with an endogenous substance. Metabolism for most anticonvulsants occurs primarily in the liver and is dependent on hepatic blood flow, enzyme activity, and protein binding. Although critical illness often inhibits the CYP450 isoenzymes, drug metabolism may be enhanced over several days as in the cases of pentobarbital and phenytoin, resulting in potential subtherapeutic concentrations [4-6]. Induced hypothermia will also reduce the systemic clearance of many medications mediated by CYP450 (such as phenytoin or propofol), between 7 and $22 \%$ for every degree of Celsius below 37 [7].

Regardless of the route of administration, renal elimination of parent drugs or metabolites is the primary excretory pathway for most drugs. For patients on renal replacement therapy (RRT), the type of dialysis that is performed and the frequency/duration should also be considered (see section 8 , special therapeutic considerations).

\section{Dosing and therapeutic drug monitoring in the ICU setting}

Dosing of AEDs should be individualized to achieve seizure control with minimal adverse effects. The 1 -h postloading dose is commonly recommended as a time to measure peak serum concentration. Pharmacokinetic alterations are frequently observed in critically ill patients; hence, frequent therapeutic drug monitoring (TDM) may be required. Basic dosing and TDM recommendations for AEDs commonly used in the ICU are summarized below and in Table 3.

\section{Phenytoin/fosphenytoin}

Phenytoin has an average half-life of $24 \mathrm{~h}$, but this ranges from 7 to $40 \mathrm{~h}$, increasing with dose escalation due to its nonlinear kinetics [8]. Phenytoin is insoluble in water and is dissolved in a basic solution including ethylene glycol, the mixture being linked to tissue necrosis ("purple hand syndrome") if extravasated [9]. Fosphenytoin, the prodrug of phenytoin, is water soluble and hence free of the toxic emulsion. This difference in solubility allows intramuscular and faster intravenous administration of fosphenytoin, but the need for plasma conversion to the active drug (phenytoin) results in a comparable time to peak plasma levels when compared with phenytoin administration itself [10].

Because phenytoin follows nonlinear or saturable metabolism pharmacokinetics, it is possible to attain excessive concentrations much easier than medications that follow linear pharmacokinetics. Phenytoin TDM is therefore clinically important in the critically ill and should be followed closely.

At normal serum levels, patients may experience minor central nervous system depression and adverse effects such as nystagmus, drowsiness, or fatigue. Beyond the normal target range, ataxia, slurred speech, and incoordination often occurs. Drug-induced seizure activity has been reported at concentrations over 50 $60 \mu \mathrm{g} / \mathrm{mL}[8]$. 
Table 2 Bioavailability and pharmacokinetic data of antiepileptic drugs [113]

\begin{tabular}{|c|c|c|c|c|c|}
\hline $\begin{array}{l}\text { Antiepileptic } \\
\text { drug agent }\end{array}$ & Bioavailability (PO formulation) & $\begin{array}{l}\text { Protein } \\
\text { binding }\end{array}$ & Half-life & Metabolism & Elimination \\
\hline Brivaracetam & Almost completely absorbed & $\leq 20 \%$ & $\sim 9 \mathrm{~h}$ & $\begin{array}{l}\text { Hydrolysis (primary route) } \\
\text { CYP2C19 }\end{array}$ & $\geq 95 \%$ renally \\
\hline Carbamazepine & $\begin{array}{l}75-85 \% \\
\text { Total daily intravenous dose should be } \\
\text { equivalent to } 70 \% \text { of previous total daily oral } \\
\text { dose }\end{array}$ & $75-95 \%$ & $\begin{array}{l}\text { Range: } 30-60 \mathrm{~h} \\
\text { After autoinduction: } \\
12-17 \mathrm{~h}\end{array}$ & $>90 \%$ by CYP3A4 & $72 \%$ renally \\
\hline Clobazam & $87 \%$ & $80-90 \%$ & 36 to $42 \mathrm{~h}$ & $\begin{array}{l}\text { Hepatic via CYP3A4 and to } \\
\text { a lesser extent via } \\
\text { CYP2C19 }\end{array}$ & $82 \%$ renally \\
\hline Clonazapam & $\sim 90 \%$ & $\sim 85 \%$ & $17-60 \mathrm{~h}$ & $\begin{array}{l}\text { Glucuronide and sulfate } \\
\text { conjugation }\end{array}$ & $\begin{array}{l}<2 \% \text { renally as } \\
\text { unchanged } \\
\text { drug }\end{array}$ \\
\hline Diazepam & $>90 \%$ & $98 \%$ & $\begin{array}{l}\text { Parent drug: } \sim 60 \text { to } 72 \mathrm{~h} \text {; } \\
\text { metabolite } \sim 152 \text { to } \\
174 \mathrm{~h}\end{array}$ & CYP3A4 and 2C19 & Renally \\
\hline Eslicarbazepine & $>90 \%$ & $<40 \%$ & $13-20 \mathrm{~h}$ & $\begin{array}{l}\text { Hydrolytic first-pass } \\
\text { metabolism }\end{array}$ & $90 \%$ renally \\
\hline Fosphenytoin & 100\% (intramuscular formulation) & $95-99 \%$ & $12-28.9 \mathrm{~h}$ & CYP2C9 CYP2C19 & Renally \\
\hline Lacosamide & $100 \%$ & $<15 \%$ & $13 \mathrm{~h}$ & CYP3A4, CYP2C9, CYP2C19 & $95 \%$ renally \\
\hline Lamotrigine & $98 \%$ & $55 \%$ & $25-70 \mathrm{~h}$ & Conjugation & $94 \%$ renally \\
\hline Levetiracetam & $100 \%$ & $<10 \%$ & $6-8 \mathrm{~h}$ & Hydrolysis & $66 \%$ renally \\
\hline Lorazepam & $90 \%$ & $\sim 91 \%$ & $12-18 \mathrm{~h}$ & Conjugation & $88 \%$ renally \\
\hline \multicolumn{6}{|l|}{ Midazolam } \\
\hline Oxcarbazepine & Readily absorbed & $40 \%$ & Active metabolite: 9-11 h & Glucoronidation & $95 \%$ renally \\
\hline Pentobarbital & - & $\begin{array}{l}45 \% \text { to } \\
70 \%\end{array}$ & $15-50 \mathrm{~h}$ & $\begin{array}{l}\text { Hydroxylation and } \\
\text { glucuronidation }\end{array}$ & $\begin{array}{l}<1 \% \text { renally as } \\
\text { unchanged } \\
\text { drug }\end{array}$ \\
\hline Perampanel & Completely and rapidly absorbed & $95 \%$ & $\sim 105 \mathrm{~h}$ & $\begin{array}{l}\text { CYP 3A4/5 primary; } \\
\text { lesser extent CYP 1A2/2B6 }\end{array}$ & $22 \%$ renally \\
\hline Phenytoin & $20-90 \%$ & $90-95 \%$ & $7-42 \mathrm{~h}$ & $\begin{array}{l}\text { CYP2C9, } 2 \text { C19 (major) and } \\
\text { 3A4 (minor) }\end{array}$ & $\begin{array}{l}<5 \% \text { renally as } \\
\text { unchanged } \\
\text { drug }\end{array}$ \\
\hline Phenobarbital & $\sim 95-100 \%$ & $50 \%$ & $\begin{array}{l}\text { Longest half-life } \\
46-136 \mathrm{~h}\end{array}$ & CYP450 and UGT mediated & $25-50 \%$ renally \\
\hline Topiramate & $80 \%$ & $15-41 \%$ & $\begin{array}{l}\text { IR: } 21 \mathrm{~h} \\
\text { ER: } 31-56 \mathrm{~h}\end{array}$ & No extensive metabolism & $70 \%$ renally \\
\hline Valproic acid & $90 \%$ & $80-90 \%$ & $9-16 \mathrm{~h}$ & $\begin{array}{l}\text { CYPs 2C9, 2C19, 2A6, UGT- } \\
\text { glucuronidation }\end{array}$ & $70-80 \%$ renally \\
\hline Zonisamide & Rapid and complete absorption & $40 \%$ & $50-68 \mathrm{~h}$ & CYP 3A4 & $60 \%$ renally \\
\hline
\end{tabular}

CYP Cytochrome, ER Extended Release, IR Immediate Release, PO By mouth, UGT Uridine diphosphate-glucuronyltransferase

Typically, protein binding accounts for $90 \%$ of total plasma concentrations, hence the therapeutic range for unbound phenytoin (free) concentrations is $1-2 \mu \mathrm{g} / \mathrm{mL}$. In patients suspected of having altered drug plasma protein binding, monitoring of free phenytoin serum concentration is of value.

\section{Valproic acid}

Although the accepted therapeutic range for total valproic acid concentration for seizure therapeutics is 50 $100 \mu \mathrm{g} / \mathrm{mL}$, levels up to $175 \mu \mathrm{g} / \mathrm{mL}$ have been suggested in cases of refractory status epilepticus (SE) cases.
Concentration-related side effects include ataxia, lethargy, tremor, and coma [11]. The common adverse effects-thrombocytopenia and hyperammonemia (via carnitine depletion) - can often be limited by dose reduction and by carnitine replacement in the latter condition. Due to significant interpatient differences in valproic acid metabolism, there is a poor correlation between valproic acid dose and total serum concentrations $[11,12]$.

Valproic acid is highly (90-95\%) protein bound and is saturable within the therapeutic range which results in higher unbound fractions at higher concentrations. 
Table 3 Dosing and monitoring of commonly used antiepileptic drugs $[8,11,15,16]$

\begin{tabular}{|c|c|c|c|c|}
\hline $\begin{array}{l}\text { Antiepileptic } \\
\text { drug }\end{array}$ & Dose & $\begin{array}{l}\text { Therapeutic } \\
\text { drug level to } \\
\text { treat epilepsy } \\
(\mu \mathrm{g} / \mathrm{mL})\end{array}$ & Monitoring & TDM clinical pearls \\
\hline Phenytoin & $\begin{array}{l}\text { Load: } 15-20 \text { mg/kg } \\
\text { Maintenance: } \\
\text { 4-6 mg/kg/day }\end{array}$ & $10-20$ & $\begin{array}{l}1 \mathrm{~h} \text { postload or } \\
\sim 7-10 \text { days after initiation of maintenance } \\
\text { dose (may check earlier within } 2-3 \text { days in } \\
\text { seizing patients to ensure their metabolism is } \\
\text { not significantly different from average patient } \\
\text { population) }\end{array}$ & $\begin{array}{l}\text { At total concentrations }>20 \mu \mathrm{g} / \mathrm{mL} \text {, } \\
\text { nystagmus may occur. } \\
\text { In concentrations }>30 \mu \mathrm{g} / \mathrm{mL} \text {, ataxia, } \\
\text { slurred speech, and incoordination } \\
\text { can be observed. } \\
\text { If total concentrations are above } 40 \\
\mu \mathrm{g} / \mathrm{mL} \text {, coma is possible. } \\
\text { At concentrations }>50-60 \mu \mathrm{g} / \mathrm{m} \text { drug } \\
\text { induced seizures may occur }\end{array}$ \\
\hline Valproic acid & $\begin{array}{l}\text { Load: } 20-40 \text { mg/kg } \\
\text { Maintenance: } \\
\text { 10-15 mg/kg/day }\end{array}$ & $\begin{array}{l}50-100 \text { (levels } \\
\text { as high as } 175 \\
\text { are used in RSE) }\end{array}$ & $\begin{array}{l}1 \mathrm{~h} \text { postload or } \\
2-4 \text { days after initiation of maintenance dose }\end{array}$ & $\begin{array}{l}\text { At total concentrations }>75 \mu \mathrm{g} / \mathrm{mL} \\
\text { lethargy and ataxia may occur. } \\
\text { In concentrations }>100 \mu \mathrm{g} / \mathrm{mL} \text { tremor } \\
\text { is observed. Coma may occur if total } \\
\text { serum concentrations are above } 175 \\
\mu \mathrm{g} / \mathrm{mL} \text {. } \\
\text { Thrombocytopenia is a dose-related } \\
\text { side effect that can be limited by re- } \\
\text { ducing the dose }\end{array}$ \\
\hline Phenobarbital & $\begin{array}{l}\text { Load: } 20 \mathrm{mg} / \mathrm{kg} \\
\text { Maintenance: } 1.5-2 \mathrm{mg} / \\
\mathrm{kg} / \text { day } \\
\text { (dose adjustment may be } \\
\text { required in liver } \\
\text { impairment due to } \\
\text { reduced clearance) }\end{array}$ & $\begin{array}{l}\text { 15-40 (higher } \\
\text { levels may be } \\
\text { utilized in RSE) }\end{array}$ & $\begin{array}{l}1 \mathrm{~h} \text { postload or } \\
4-7 \text { days after initiation of maintenance dose }\end{array}$ & $\begin{array}{l}\text { CNS depression is a dose-related side } \\
\text { effect. In concentrations }>60 \mu \mathrm{\mu g} / \mathrm{mL} \\
\text { respiratory depression may occur }\end{array}$ \\
\hline Pentobarbital & $\begin{array}{l}\text { Load: } 5-15 \mathrm{mg} / \mathrm{kg} \\
\text { Maintenance: } 0.5-5 \mathrm{mg} / \\
\mathrm{kg} / \mathrm{h}\end{array}$ & $\begin{array}{l}\text { 1-5 (rarely used } \\
\text { to assess clinical } \\
\text { efficacy or } \\
\text { toxicity) }\end{array}$ & $\begin{array}{l}\text { May be used after discontinuation to monitor } \\
\text { the residual effects of the drug }\end{array}$ & $\begin{array}{l}\text { Drug levels have not been correlated } \\
\text { with electroencephalography } \\
\text { CNS depression, respiratory } \\
\text { depression, and hemodynamic } \\
\text { instability are dose-related side effects }\end{array}$ \\
\hline
\end{tabular}

CNS central nervous system, RSE Refractory Status Epilepticus, TDM therapeutic drug monitoring

Although not often monitored, a therapeutic free valproic acid range of $2.5-10 \mu \mathrm{g} / \mathrm{mL}$ can be used as an initial guide [11].

\section{Phenobarbital}

Phenobarbital has a long half-life of approximately $100 \mathrm{~h}$, which limits its use when short-term AED use is desired. As with other AEDs, treatment of SE in particular may require higher than normal dosing, and this may reach upwards of even $10 \mathrm{mg} / \mathrm{kg} /$ day (serum levels of $>100 \mu \mathrm{g} / \mathrm{mL}$ ) with solid efficacy demonstrated [13]. Concentration-related adverse effects of phenobarbital are sedation, confusion, and lethargy, with high doses leading to obtundation and respiratory depression [14]. As phenobarbital is only about $50 \%$ protein-bound, free drug monitoring is not warranted. However, in severe hepatic impairment (Child-Pugh score > 8) a decrease of $25-50 \%$ in the initial daily maintenance dose may be required [15].

\section{Pentobarbital}

Pentobarbital is often used in the ICU setting to treat SE or elevated intracranial pressure. Initiation of pentobarbital involves sequential bolus doses followed by a continuous infusion [16, 17]. The average half-life of pentobarbital in adults is reported to be about $22 \mathrm{~h}$ and it is $20-45 \%$ protein-bound. Serum pentobarbital TDM (reference range is $1-5 \mu \mathrm{g} / \mathrm{mL}$ ) is of limited utility in determining treatment clinical response or toxicity; the direct measure of intracranial pressure (ICP) control or inducement of "burst suppression" by electroencephalography (EEG) are monitored instead. Serum concentrations, however, may be useful in assessing residual effects of pentobarbital-induced coma once discontinued [18].

\section{Drug-drug interactions AED-AED drug interactions}

Administration of multiple AEDs is common in the ICU to manage refractory seizures and SE. Satisfactory seizure control is not achieved in $30-40 \%$ of patients with monotherapy, making it necessary to use two or more AEDs [19, 20]. Although synergistic anticonvulsant activity between medications may be desirable, concurrent use of multiple AEDs generally increases the risk of drug interactions. Table 4 lists common AED-AED drug-drug interactions. 
Table 4 AED-AED drug interactions [113-116]

\begin{tabular}{|c|c|c|c|c|c|c|c|c|c|c|c|c|c|}
\hline & CBZ & CNP & DZP & LAC & LAM & MDZ & OXZ & PEN & PMP & PHB & PHT & PFL & TOP \\
\hline \multirow[t]{2}{*}{ ZON } & $\downarrow \mathrm{ZON}$ & & & $\downarrow L A C$ & & & $\downarrow Z O N$ & $\downarrow Z O N$ & & $\downarrow \mathrm{ZON}$ & $\downarrow Z O N$ & & $\downarrow Z O N$ \\
\hline & $\uparrow C B Z$ & & & & & & & & & & & & \\
\hline \multirow[t]{2}{*}{ VPA } & $\downarrow V P A$ & ? risk of absence seizures & & & $\uparrow \mathrm{LAM}$ & & $\downarrow O X Z$ & & $\uparrow V P A$ & $\uparrow P H B$ & $\uparrow \mathrm{PHT}$ & $\uparrow P F L$ & $\downarrow V P A$ \\
\hline & $\uparrow C B Z$ & & & & & & & & & $\downarrow V P A$ & $\downarrow V P A$ & & \\
\hline \multirow[t]{2}{*}{ TOP } & $\downarrow V P A$ & & $\uparrow \mathrm{DZP}$ & & & $\downarrow M D Z$ & & $\downarrow T O P$ & $\downarrow \mathrm{PMP}$ & $\downarrow$ TOP & $\uparrow \mathrm{PHT}$ & & \\
\hline & $\downarrow$ TOP & & & & & & & & & & $\downarrow T O P$ & & \\
\hline \multirow[t]{2}{*}{ PHT } & $\downarrow \uparrow C B Z$ & & $\downarrow D Z P$ & $\downarrow L A C$ & $\downarrow L A M$ & $\downarrow M D Z$ & & $\downarrow P E N$ & $\downarrow \mathrm{PMP}$ & $\downarrow \mathrm{PHT}$ & & & \\
\hline & $\downarrow \uparrow P H T$ & & & & & & & & & & & & \\
\hline PHB & $\downarrow C B Z$ & & $\downarrow D Z P$ & & $\downarrow L A M$ & $\downarrow M D Z$ & $\downarrow O X Z$ & & & & & & \\
\hline PEN & $\downarrow C B Z$ & & $\downarrow D Z P$ & & & $\downarrow M D Z$ & & & & & & & \\
\hline \multirow[t]{2}{*}{ OXZ } & $\downarrow C B Z$ & & $\uparrow \downarrow D Z P$ & & & $\downarrow M D Z$ & & & & & & & \\
\hline & $\downarrow O X Z$ & & & & & & & & & & & & \\
\hline MDZ & $\downarrow M D Z$ & & & & & & & & & & & & \\
\hline LAM & $\downarrow L A M$ & & & & & & & & & & & & \\
\hline LAC & $\downarrow L A C$ & & & & & & & & & & & & \\
\hline \multirow[t]{2}{*}{ DZP } & $\downarrow D Z P$ & & & & & & & & & & & & \\
\hline & $\uparrow C B Z$ & & & & & & & & & & & & \\
\hline \multicolumn{14}{|l|}{ CNP } \\
\hline BRV & $\downarrow B R V$ & & & & & & & & & & & & \\
\hline
\end{tabular}

$\uparrow$ and $\downarrow$ indicate increased and decreased levels and/or effects, respectively

$A E D$ antiepileptic drug, CBZ carbamazepine, CNP clonazepam, GBT gabapentine, GTC generalized tonic-clonic, $L A C$ lacosamide, $L A M$ lamotrigine, $L E V$ levetiracetam, OXZ oxcarbazepine, PMP perampanel, PHB phenobarbital, $P H T$ phenytoin, $P G B$ pregabalin, TOP topiramate, VPA valproic acid, ZON zonisamide

\section{AED-nonAED interactions}

Interactions of AEDs with other agents is seen more frequently with drugs that are metabolized in the liver, and therefore are more common with older AEDs. Tables 5 and 6 describe AED-nonAED and nonAED-AED interactions.

\section{Seizure prevention in the ICU}

\section{Traumatic brain injury}

The incidence of post-traumatic seizures accounts for $6 \%$ of overall symptomatic epilepsy [21-23] and is estimated to occur in up to $15 \%$ and $53 \%$ in civilian and military populations, respectively $[24,25]$. Clinical studies have divided post-traumatic seizures into either immediate $(<24 \mathrm{~h})$, early (within 1 week, with a seizure incidence of $2.1-16.9 \%$ ), or late (with an incidence of $1.9 \%$ to $>30.0 \%)[22,23,26])$.

Early seizures occur in about $10-15 \%$ of patients not treated with anticonvulsants, and this incidence can be reduced to about $2-3 \%$ with the use of phenytoin [27]. There is, however, little evidence that such use reduces the occurrence of late seizures or the incidence of death and neurologic disability [28]. It thus appears that anticonvulsants are suppressive during the early period following traumatic brain injury (TBI), but are not prophylactic for the time period beyond the first week. The American Academy of Neurology (AAN) [29] and the Brain Trauma
Foundation [30] advocate prophylactic use of AED only during the first 7 days after a head injury [31, 32]. Phenytoin has been shown to decrease the incidence of early post-traumatic seizures [30] and to be more cost-effective than levetiracetam [33]. Although levetiracetam was shown in small early studies to be as effective as phenytoin $[33,34]$, there are recent data suggesting a lack of any prophylactic action in a comparative study of levetiracetam versus no prophylaxis [35]. A trial that incorporated a blinded design and the use of continuous electroencephalography (cEEG) monitoring demonstrated no difference in early or late seizure incidence between drugs, but did favor levetiracetam over phenytoin in the 6-month Glasgow Outcome score measure [36].

The use of valproic acid, as compared with phenytoin, failed to demonstrate benefit and its use correlated with higher mortality [37]. However, a recent Cochrane analysis failed to discriminate between phenytoin and other anticonvulsants with regards to reduced incidence or mortality [37].

\section{Ischemic stroke}

Seizures following ischemic stroke occur within an incidence range of $4 \%$ to $14 \%$ [38-40]. According to a large recent registry from France, early seizures are not associated with higher mortality or unfavorable outcomes at 1 month 
Table 5 Interaction of selected antiepileptic drugs with commonly used medications in the intensive care unit $[113,115,117-124]$

\begin{tabular}{|c|c|c|}
\hline $\begin{array}{l}\text { Antiepileptic } \\
\text { drug }\end{array}$ & Therapeutic group & Selected examples \\
\hline $\begin{array}{l}\text { Phenytoin, } \\
\text { phenobarbital, } \\
\text { carbamazepine }\end{array}$ & Psychotropic agents & $\begin{array}{l}\downarrow \text { Amitriptyline, nortriptyline, } \\
\text { imipramine, bupropion, } \\
\text { paroxetine, citalopram, } \\
\text { Haloperidol, chlorpromazine, } \\
\text { olanzapine, risperidone, } \\
\text { quetiapine, ziprasidone }\end{array}$ \\
\hline Valproic acid & & $\begin{array}{l}\uparrow \text { Amitriptyline, nortriptyline, } \\
\text { paroxetine }\end{array}$ \\
\hline Topiramate & & $\uparrow$ Haloperidol \\
\hline $\begin{array}{l}\text { Phenytoin, } \\
\text { phenobarbital, } \\
\text { carbamazepine }\end{array}$ & Antimicrobials & $\begin{array}{l}\downarrow \text { Doxycycline, metronidazole, } \\
\text { itraconazole, retrovirals }\end{array}$ \\
\hline Valproic acid & & $\uparrow$ Zidovudine \\
\hline Phenytoin & $\begin{array}{l}\text { Cardiovascular } \\
\text { agents }\end{array}$ & $\begin{array}{l}\downarrow \text { Amiodarone, nimodipine, } \\
\text { diltiazem, verapamil, ticagrelor, } \\
\text { atorvastatin, dabigatran, } \\
\text { apixaban, rivaroxaban ( } \uparrow \\
\text { warfarin effects with } \\
\text { phenytoin load, } \downarrow \text { warfarin } \\
\text { effects with maintenance dose } \\
\text { of phenytoin) }\end{array}$ \\
\hline Lacosamide & & $\begin{array}{l}\text { Diltiazem, verapamil (risk of } \\
\text { atrioventricular block/ } \\
\text { bradycardia), } \downarrow \text { warfarin }\end{array}$ \\
\hline Carbamazepine & & $\begin{array}{l}\downarrow \text { Nimodipine, diltiazem, } \\
\text { verapamil, ticagrelor, } \\
\text { atorvastatin, warfarin, } \\
\text { dabigatran, apixaban and } \\
\text { rivaroxaban }\end{array}$ \\
\hline Phenobarbital & & $\downarrow$ Nimodipine, atorvastatin \\
\hline Valproic acid & & $\uparrow$ Nimodipine, warfarin \\
\hline $\begin{array}{l}\text { Phenytoin, } \\
\text { phenobarbital, } \\
\text { carbamazepine }\end{array}$ & Analgesics & $\downarrow$ Fentanyl, methadone \\
\hline $\begin{array}{l}\text { Phenytoin, } \\
\text { phenobarbital, } \\
\text { carbamazepine }\end{array}$ & Immunosuppressant & $\begin{array}{l}\downarrow \text { Cyclosporine, sirolimus, } \\
\text { tacrolimus, corticosteroids }\end{array}$ \\
\hline
\end{tabular}

$\uparrow$ and $\downarrow$ indicate increased and decreased levels and/or effects, respectively a The interaction between phenytoin and warfarin is complicated and unpredictable. Close monitoring of the international normalized ratio (INR) as well as serum phenytoin levels are critical if this combination is clinically necessary. Upon initiation of phenytoin, there may be transient increases in the INR as a result of protein binding displacement of warfarin by phenytoin, and enhanced anticoagulant effect. This may be followed by a reduction in anticoagulant activity as result of phenytoin's induction of warfarin metabolism $[125,126]$

or at 1 year [41]. Patients with late-onset seizures have a greater than twice the risk for subsequent stroke, although the causal relationship is unclear [42].

Given the rather low incidence of seizures following most ischemic stroke syndromes, neither the American Heart Association (AHA) nor the American Stroke Association guidelines recommend prophylactic use of anticonvulsants following ischemic stroke [43]. However, some patients may be at greater risk for seizures. An
Table 6 Interaction of selected therapeutic classes with antiepileptic drugs $[115,117,127-132]$

\begin{tabular}{|c|c|c|}
\hline Therapeutic class & Selected examples & Antiepileptic drugs \\
\hline \multirow[t]{3}{*}{ Psychotropic agents } & $\begin{array}{l}\text { Fluoxetine, sertraline, } \\
\text { trazodone }\end{array}$ & 个 Phenytoin \\
\hline & $\begin{array}{l}\text { Trazodone, fluoxetine, } \\
\text { risperidone }\end{array}$ & $\uparrow$ Carbamazepine \\
\hline & Sertraline & $\uparrow$ Valproic acid \\
\hline \multirow[t]{4}{*}{ Antimicrobials } & $\begin{array}{l}\text { Erythromycin, } \\
\text { clarithromycin, } \\
\text { ketoconazole, } \\
\text { fluconazole }\end{array}$ & $\uparrow$ Carbamazepine \\
\hline & Ritonavir & \\
\hline & Sulfonamides & $\uparrow$ Phenytoin \\
\hline & $\begin{array}{l}\text { Carbapenems } \\
\text { (imipenem, } \\
\text { doripenem, } \\
\text { meropenem, } \\
\text { ertapenem) }\end{array}$ & $\downarrow$ Valproic acid \\
\hline \multirow[t]{3}{*}{$\begin{array}{l}\text { Cardiovascular } \\
\text { agents }\end{array}$} & Amiodarone & $\begin{array}{l}\uparrow \text { Phenytoin (a dose } \\
\text { reduction of } \\
\text { approximately } 25 \% \text { is } \\
\text { recommended) }\end{array}$ \\
\hline & Diltiazem & $\begin{array}{l}\uparrow \text { Carbamazepine, } \\
\text { phenytoin (risk of } \\
\text { toxicity) }\end{array}$ \\
\hline & Clopidogrel & $\uparrow$ Phenytoin \\
\hline Analgesics & Acetaminophen & $\downarrow$ Lamotrigine \\
\hline Immunosuppressants & Methotrexate & $\begin{array}{l}\downarrow \text { Valproic acid, } \\
\text { carbamazepine }\end{array}$ \\
\hline
\end{tabular}

$\uparrow$ and $\downarrow$ indicate increased and decreased levels and/or effects, respectively

increase in seizure risk has been reported following cardioembolism [39], hyperglycemia [41], intravenous thrombolysis with alteplase [44], in patient with SE following poststroke seizures, and either large cortical or hemorrhagic infarction [38, 45-48].

If "prophylaxis" is considered, then the agent used should be selected for its adverse effect profile. In recent years there has been some interest in ascribing statins as a "first-line" anticonvulsant in stroke patients, although supportive data are by association only and this type of intervention is not readily practiced $[49,50]$.

\section{Intracerebral hemorrhage}

In contrast to ischemic stroke, intracerebral hemorrhage $(\mathrm{ICH})$ portends a somewhat higher risk of seizures, ranging from two- to seven-times that from ischemic stroke $[38,47,51,52]$. If cEEG is performed during the acute admission period, nonconvulsive epileptiform activity is commonly observed and may affect more than $20 \%$ of ICH patients [53-56]. As expected, lobar or supratentorial ICHs have the highest incidence of seizures; those in the posterior fossa have almost zero [38, 54]. Surgical evacuation confers an increased incidence, and subarachnoid or subdural blood also increases the risk for seizures [57]. 
Prophylactic anticonvulsant treatment in $\mathrm{ICH}$ patients is currently not strongly advocated. cEEG is suggested by some for ICH patients with a depressed mental status out of proportion to that expected for the severity of the stroke [58]. Levetiracetam has become the most widely prescribed agent despite a lack of evidence [59], likely due to its ease of use. Uncontrolled study data have suggested that phenytoin confers worse outcomes than others (primarily against levetiracetam) [60-62], but these data are not supported by other recent studies $[63,64]$.

\section{Subarachnoid hemorrhage}

Early and late-onset seizures are observed in patients with subarachnoid hemorrhage (SAH). Risk factors include the severity of SAH, concomitant intracerebral or intraventricular blood, and treatment with craniotomy [65]. A recent study noted a $10 \%$ incidence of seizures, with almost half (47\%) occurring within the initial $24 \mathrm{~h}$ [66]. Interestingly, the use of prophylactic anticonvulsants did not reduce the overall risk. As seizures dramatically increase cerebral blood flow and blood pressure, rebleeding from a recently ruptured aneurysm during seizures may pose a serious risk.

Current guidelines from the AHA state that the use of anticonvulsants for a brief period is reasonable, without specific drug recommendation [67]. Beyond the immediate posthemorrhagic period, routine use of anticonvulsants is advocated by the AHA only in patients with a high risk for delayed seizures, such as prior seizure, intracerebral hematoma, intractable hypertension, infarction, or middle cerebral artery aneurysm. The Neurocritical Care Society (NCS) specifically recommended against the routine use of phenytoin for prophylaxis [68].

\section{Brain tumors}

The incidence of seizures in cerebral malignancy broadly ranges from about $10 \%$ to as high as $90 \%$, and is correlated with tumor type (glioma and oligodendroglioma being amongst the highest risk) and also the rate of progression, with slow growing tumors tending towards higher seizure incidence [69]. Prophylactic use of AEDs in brain tumors remains controversial. There are strikingly little data in support of seizure prophylaxis for brain tumor patients [70-72], and guidelines by the AAN and the European Federation of Neurosciences do not support this practice $[73,74]$. Since these guidelines were written prior to the widespread use of cEEG and prior to the introduction of newer, less toxic anticonvulsants (levetiracetam, lamotrigine, lacosamide, and so forth), some have suggested that such a recommendation should be reassessed [75].

Whenever patients require adjuvant chemotherapy, it is prudent to avoid the use of potent CYP3A4 coenzyme inducers such as carbamazepine, phenytoin, and phenobarbital because of the risks of compromising concurrent chemotherapy [74]. Based on more recent evidence, more patients are being managed with levetiracetam than phenytoin or sodium valproate [71], but evidence of superior efficacy remains absent [72].

\section{Cerebral venous and sinus thrombosis}

Seizures manifest as a common presentation, occurring in $29 \%$ to $50 \%$ of patients with cerebral venous sinus thrombosis [76, 77]. Approximately a third to one half of seizures occur early-as the presenting symptom or within 2 weeks of diagnosis, [77-79]. Despite the lack of controlled studies, prophylaxis appears prudent where forthcoming seizures appear highly probable. There is some evidence that early seizures are predictive of a remote epilepsy condition [80] but, in and of themselves, seizures in the context of cerebral venous sinus thrombosis do not appear to be associated with death or 6-month worse outcomes [81].

\section{Seizure control in the ICU}

The widespread use of cEEG has made it apparent that seizures are more common in the ICU patients than previously thought, with estimates for seizures and SE ranging from $19 \%$ to $27 \%[82,83]$. Bauer and Trinka introduced the distinction between nonconvulsive status epilepticus (NCSE) proper and comatose NCSE [84]. This distinction is both important and useful as it acknowledges that treatment as well as prognosis are dependent on the underlying epileptic syndrome in the former, yet on the underlying cause of the coma in the latter. In the ICU patient population, the electrographic seizure patterns can be less distinct and harder to identify. Thus, a body of literature on the nature of, and the best treatment approach for, the "ictal-interictal continuum" has emerged and now dominates the literature. For recent reviews, see Sivaraju and Gilmore 2016 [85] and Rodríguez et al. 2016 [86].

As a general principle, the current consensus is that treatment of even a single ICU seizure should occur in order to prevent escalation into SE. Once airway, breathing, circulation, and "dextrose" (the "ABCDs") have been addressed, pharmacologic seizure treatment should occur immediately. Several authors suggest an algorithm that escalates from first-line to second-line treatment in the time span of $30 \mathrm{~min}$ [87, 88]. Once urgent first- and second-line agents are prescribed during the first $30 \mathrm{~min}$, persistent SE should be considered refractory, and this should prompt the use of intravenous anesthetic therapy. SE is a neurological emergency and swift intervention is of the essence. While convulsive and nonconvulsive SE should be initially approached in the same way, once the need for intubation arises it is generally accepted that NCSE may warrant a less aggressive and more individualized approach to treatment with anesthetic agents (third-line agents) compared with convulsive SE. 
Available evidence uniformly suggests that benzodiazepines remain the drugs of choice for the immediate control of seizures of any kind. The efficacy of intravenous lorazepam was demonstrated by Treiman et al. in 1998 [89]. Lorazepam was most effective in the initial treatment of convulsive SE when compared with phenobarbital and diazepam plus phenytoin, although the latter were also effective. Other routes for the administration of benzodiazepines have successfully been explored, particularly for the therapy of seizures encountered outside the ICU. Silbergleit et al. reported that intramuscular midazolam was at least as safe and effective as intravenous lorazepam for prehospital seizure cessation [90], while McIntyre et al. demonstrated the efficacy of buccal midazolam [91].

Although an open-label use study purported to suggest equipoise between lorazepam and levetiracetam in the treatment of SE [92], a randomized, double-blind, placebo-controlled trial (SAMU Keppra Trial) failed to show benefit from adding intravenous levetiracetam to clonazepam in the treatment of generalized convulsive SE [93].

To monitor for ongoing seizure activity after convulsions may have ceased, cEEG is crucial. Second-line therapy for SE should be initiated within $30 \mathrm{~min}$ if first-line treatment has failed. Agents used as second-line therapy include fosphenytoin, valproic acid, phenobarbital, and levetiracetam. Evidence for the superiority of one over the other is generally lacking [94]. Nonetheless, phenytoin has been the most studied drug in SE and is therefore often listed as the preferred choice over the others. Valproic acid is notable for being the only agent that has shown a trend towards superior efficacy in some studies but this has not been confirmed in a large-scale trial [95]. Levetiracetam has a favorable side-effect profile and is therefore increasingly prescribed as a second-line drug. Phenobarbital is often avoided due to its long half-life, although data support its efficacy [89]. Lacosamide has recently shown promise in small case studies [96], while brivaracetam is currently under investigation [97].

If second-line agents are ineffective, treatment is typically escalated to anesthetic agents. For patients in NCSE, however, the decision whether or not to intubate and sedate the patient will usually be made on a case-by-case basis. There is some evidence to suggest that uncontrolled NCSE will result in brain damage over time [98]. Furthermore, DeLorenzo et al. noted that persistent NCSE after convulsive status may carry a worse prognosis than other forms of nonconvulsive status and perhaps should be treated more aggressively, although the presence of NCSE may simply be a marker for more severe brain injury [99]. Agents used for continuous infusion are midazolam, propofol, and pentobarbital, with no data suggesting the superiority of one over the other [100]. Ultimately, it is important not only to treat the patient with an anesthetic agent but to also continue maintenance therapy with appropriate AEDs to allow transition to a well-tolerated, long-term antiepileptic regimen.

\section{Drugs lowering seizure threshold}

Polypharmacy is common in the ICU and can contribute to adverse drug effects such as seizures by lowering the seizure threshold or via drug-drug interactions that may reduce the blood concentration of an AED the patient may already be receiving (see the next section). Antibiotics, psychotropic agents, and analgesics have been all associated with seizures $[101,102]$ (Table 7).

\section{Special therapeutic considerations}

\section{Extracorporeal removal of antiepileptic drugs} Antiepileptic drug removal by renal replacement therapies

The renal route of elimination, low protein binding, low volume of distribution, and molecular weight are physiochemical factors that impact the propensity for drug removal via dialysis (Table 8). Unfortunately, kinetic data on optimal dosing of AEDs in RRT are not readily available. Clearly such patients benefit from careful TDM and a multidisciplinary approach. There are extensive expert reviews available in the medical literature $[103,104]$.

Intermittent hemodialysis The removal of most AEDs by intermittent hemodialysis (IHD) is usually well characterized in the drug's labeled prescribing information or other references. Two common drugs that are removed by IHD and for which data recommendations exist are levetiracetam and lacosamide. In addition, while phenobarbital is predominantly hepatically metabolized, some reports suggest partial elimination by IHD prompting several experts to suggest supplemental dosing after IHD and monitoring of serum drug levels [103, 105, 106].

Continuous renal replacement therapy There is insufficient evidence to recommend clear dosing guidelines for AEDs in continuous renal replacement therapy (CRRT), and more research is needed to appropriately guide therapy. AEDs that are eliminated via IHD will also be eliminated by CRRT, often times even more so (depending on the duration of CRRT as well as the mode and flow rates) thereby requiring higher doses. For drugs where serum levels are available, TDM is indicated. Estimations of drug removal can be performed to estimate the removal of medications by CRRT based on flow rates, as well as drug and filter properties. The reader is referred to other resources for a more comprehensive discussion on these methods $[107,108]$. A recent review of the literature proposed dosing recommendations based on AED protein binding and the extent of renal versus hepatic elimination [104]. This is a reasonable approach, although clinicians should also factor in CRRT 
Table 7 Selected list of medications associated with lower seizure threshold [113]

\begin{tabular}{|c|c|c|c|c|}
\hline Antibiotics & Psychotropic agents & Analgesics & Neurostimulants & Miscellaneous agents \\
\hline Cefepime & Bupropion & Meperidine $^{b}$ & Amantadine & Baclofen \\
\hline Erythromycin & Haloperidol & Tramadol & Amphetamines & Flumazenil \\
\hline Imipenem $^{\mathrm{a}}$ & Phenothiazines & & Bromocriptine & \\
\hline Isoniazid & SSRIS & & & \\
\hline Levofloxacin & TCAs & & & \\
\hline \multicolumn{5}{|l|}{ Linezolid } \\
\hline \multicolumn{5}{|l|}{ Meropenem } \\
\hline \multicolumn{5}{|l|}{ Metronidazole } \\
\hline Penicillins & & & & \\
\hline
\end{tabular}

SSRI selective serotonin reuptake inhibitor, TCA tricyclic antidepressant

${ }^{a}$ Carbapenems have been reported to have the highest rate of seizure among all drugs

${ }^{b}$ Normeperidine, the active metabolite of meperidine, has been associated with seizures and accumulates in renal failure

flow rates, the clinical condition of the patient, and other factors into their clinical decision making accordingly.

\section{Antiepileptic drug removal by plasmapheresis}

In the neurocritical care unit, plasmapheresis (PLEX) is often employed to manage neuroautoimmune diseases. Unlike RRT, which removes the free fraction of a drug, PLEX removes whole plasma which includes both the free fraction of a drug as well as the protein-bound portion. Thus, a key factor in determining the whole body removal of a drug with PLEX is its volume of distribution. Other factors can include the duration/frequency of PLEX and exchange volume, as well as the rate of intercompartmental equilibration. In general, drugs with low volumes of distribution $(<0.2 \mathrm{~L} / \mathrm{kg})$ predominantly reside in the vascular compartment and PLEX would be expected to remove a significant portion of the total body stores of these drugs. As for AEDs with high volumes of distribution such as phenytoin, PLEX appears to remove only about 2.5$10 \%$ of total body phenytoin $[109,110]$.

\section{Antiepileptic drug removal by extracorporeal membrane oxygenation}

Extracorporeal membrane oxygenation (ECMO) can impact the pharmacokinetics of drugs in a number

Table 8 Factors impacting drug removal by renal replacement therapies

\begin{tabular}{|c|c|}
\hline Drug-related factors & RRT-related factors \\
\hline - Low protein binding & $\begin{array}{l}\text { - Mode of dialysis (CRRT vs. IHD vs. } \\
\text { others) }\end{array}$ \\
\hline - Low volume of distribution & $\begin{array}{l}\text { - RRT filter membrane (sieving } \\
\text { coefficient) }\end{array}$ \\
\hline $\begin{array}{l}\text { - Predominantly renally } \\
\text { eliminated }\end{array}$ & $\begin{array}{l}\text { - Dialysis prescription (mode and flow } \\
\text { rates) }\end{array}$ \\
\hline - Low molecular weight & $\begin{array}{l}\text { - Duration/frequency of renal } \\
\text { replacement }\end{array}$ \\
\hline
\end{tabular}

CRRT continuous renal replacement therapy, IHD intermittent hemodialysis, $R R T$ renal replacement therapy of ways. ECMO circuits are well known to sequester drugs given the large surface area of the tubing and membranes which can result in an increase in the volume of distribution initially [111], while later releasing the drug into the circulation resulting in an unpredictable effect [112]. Lipophilic and highly protein-bound drugs are considered to be particularly vulnerable, but other physiochemical factors such as molecular weight, protein binding, and ionization may all play a role [113]. In addition, ECMO is typically associated with reduced drug clearance as a result of alterations of end-organ perfusion. ECMO is also often combined with some form of RRT, further complicating predictability. One case report suggests ECMO has little impact on the disposition of levetiracetam (which has a low volume of distribution and low protein binding) [114]. Where available, clinicians should monitor serum levels to guide dosing in patients on AEDs.

\section{Conclusion}

Selection of the most appropriate AED in the ICU setting can be challenging for a variety of reasons. Older AEDs such as phenytoin, valproic acid, and phenobarbital are often used by clinicians due to their familiarity with these agents, intravenous formulations, and availability of evidence in certain clinical scenarios. Despite this, adverse effects of these agents, drug-drug interactions, and the need for TDM may limit their use. Newer agents such as levetiracetam and lacosamide are gaining popularity due to their relatively safe AED profile, fewer drug-drug interactions, and lack of need for TDM. The efficacy of these agents for seizure prophylaxis and as second-line treatment for SE, however, should be further evaluated in large randomized clinical trials. 


\section{Abbreviations}

AAN: American Academy of Neurology; AED: Antiepileptic drug; AHA: American Heart Association; cEEG: Continuous electroencephalography; CRRT: Continuous renal replacement therapy; CYP450: Cytochrome P450; ECMO: Extracorporeal membrane oxygenation; EEG: Electroencephalography; GABA: Gamma-aminobutyric acid; ICH: Intracerebral hemorrhage; ICP: Intracranial pressure; ICU: Intensive care unit; IHD: Intermittent hemodialysis; NCSE: Nonconvulsive status epilepticus; PLEX: Plasmapheresis; RRT: Renal replacement therapy; SAH: Subarachnoid hemorrhage; SE: Status epilepticus; TBI: Traumatic brain injury; TDM: Therapeutic drug monitoring

\section{Availability of data and materials}

Data sharing is not applicable to this article as no datasets were generated or analyzed during the current study.

\section{Authors' contributions}

SF participated in the design of this work and started the outlines of this review article. In addition, she independently worked on the pharmacokinetics/ pharmacodynamics section, drug monitoring, drugs lowering the seizure threshold, abstract, conclusion, and the references. PT-F participated in the design and outlines of this review paper. He also independently created the table on AED-AED drug interactions. EKR independently wrote the section on the seizure control in the ICU and reviewed all other sections as well. JJL independently wrote the section on special therapeutic considerations and helped with the design of the manuscript. MAM independently worked on seizure prevention in the ICU and reviewed the manuscript for format, word count, and references. All authors have read and approved the manuscript.

\section{Ethics approval and consent to participate}

Not applicable.

\section{Competing interests}

The authors declare that they have no competing interests.

\section{Publisher's Note}

Springer Nature remains neutral with regard to jurisdictional claims in published maps and institutional affiliations.

\section{Author details}

'Department of Pharmacy, The Johns Hopkins Hospital, 600 N. Wolfe Street, Carnegie 180, Baltimore, MD 21287, USA. ²Department of Neurology, The Johns Hopkins Hospital, Baltimore, MD, USA. ${ }^{3}$ Department of Anesthesiology and Critical Care Medicine, The Johns Hopkins Hospital, Baltimore, MD, USA. ${ }^{4}$ Department of Medicine, Virginia Commonwealth University School of Medicine, INOVA Campus, Falls Church, VA, USA.

\section{Received: 24 January 2018 Accepted: 14 May 2018}

\section{Published online: 07 June 2018}

\section{References}

1. Varelas PN, Spanaki MV, Mirski MA. Seizures and the neurosurgical intensive care unit. Neurosurg Clin N Am. 2013;24(3):393-406.

2. Voils SA, Human T, Brophy GM. Adverse neurologic effects of medications commonly used in the intensive care unit. Crit Care Clin. 2014;30(4):795811.

3. Lee JW, Dworetzky B. Rational polytherapy with antiepileptic drugs. Pharmaceuticals. 2010;3(8):2362-79.

4. Boucher BA, Hanes SD. Pharmacokinetic alterations after severe head injury. Clin Pharmacokinet. 1998;35(3):209-21.

5. Boucher $B A$, et al. Phenytoin pharmacokinetics in critically ill trauma patients. Clin Pharmacol Ther. 1988;44(6):675-83.

6. McKindley DS, et al. Effect of acute phase response on phenytoin metabolism in neurotrauma patients. J Clin Pharmacol. 1997;37(2):129-39.

7. Arpino PA, Greer DM. Practical pharmacologic aspects of therapeutic hypothermia after cardiac arrest. Pharmacotherapy. 2008;28(1):102-11.

8. Bauer LA. Phenytoin/fosphenytoin. In: Applied clinical pharmacokinetics, 3e. New York: McGraw-Hill Medical; 2015.

9. Spengler RF, et al. Severe soft-tissue injury following intravenous infusion of phenytoin: Patient and drug administration risk factors. Arch Intern Med. 1988;148(6):1329-33.
10. Millares-Sipin CA, Alafris A, Cohen H. Phenytoin and fosphenytoin, in casebook. In: Cohen H, editor. Clinical pharmacokinetics and drug dosing. New York: McGraw-Hill Education; 2015.

11. Bauer LA. Valproic acid. In: Applied clinical pharmacokinetics, 3e. New York: McGraw-Hill Medical; 2015.

12. Bauer $L A$, et al. Valproic acid clearance: unbound fraction and diurnal variation in young and elderly adults. Clin Pharmacol Ther. 1985;37(6):697-700.

13. Mirski MA, Williams MA, Hanley DF. Prolonged pentobarbital and phenobarbital coma for refractory generalized status epilepticus. Crit Care Med. 1995;23(2):400-4.

14. Rogers SJ, Cavazos JE. Chapter 40. Epilepsy. In: DiPiro JT, et al., editors. Pharmacotherapy: a pathophysiologic approach, 9e. New York: The McGraw-Hill Companies; 2014.

15. Bauer LA. Phenobarbital/primidone. In: Applied clinical pharmacokinetics, 3e. New York: McGraw-Hill Medical; 2015.

16. Eisenberg $\mathrm{HM}$, et al. High-dose barbiturate control of elevated intracranial pressure in patients with severe head injury. J Neurosurg. 1988;69(1):15-23.

17. Wermeling DP, et al. Pentobarbital pharmacokinetics in patients with severe head injury. Drug Intell Clin Pharm. 1987;21(5):459-63.

18. Huynh F, Mabasa VH, Ensom MH. A critical review: does thiopental continuous infusion warrant therapeutic drug monitoring in the critical care population? Ther Drug Monit. 2009;31(2):153-69.

19. Kwan P, Brodie MJ. Combination therapy in epilepsy. Drugs. 2006;66(14): $1817-29$.

20. Kwan P, Brodie MJ. Effectiveness of first antiepileptic drug. Epilepsia. 2001; 42(10):1255-60.

21. Temkin NR. Preventing and treating posttraumatic seizures: the human experience. Epilepsia. 2009;50(s2):10-3.

22. Herman ST. Epilepsy after brain insult targeting epileptogenesis. Neurology. 2002;59(9 suppl 5):S21-6.

23. Pitkänen A, Bolkvadze T. Head trauma and epilepsy. Epilepsia. 2010;51(s5):31.

24. Traumatic Brain Injury. Available from: http://www.cdc.gov/ TraumaticBrainInjury/index.html. Accessed 14 Jan 2018.

25. Lee S-T, et al. Early seizures after moderate closed head injury. Acta Neurochir. 1995;137(3-4):151-4.

26. Frey LC. Epidemiology of posttraumatic epilepsy: a critical review. Epilepsia. 2003;44(s10):11-7.

27. Temkin NR, et al. A randomized, double-blind study of phenytoin for the prevention of post-traumatic seizures. N Engl J Med. 1990;323(8):497-502.

28. Schierhout G, Roberts I. Prophylactic antiepileptic agents after head injury: a systematic review. J Neurol Neurosurg Psychiatry. 1998;64(1):108-12.

29. Chang BS, Lowenstein DH. Antiepileptic drug prophylaxis in severe traumatic brain injury. Neurology. 2003;61(8):1162.

30. Bratton $\mathrm{S}$, et al. Guidelines for the management of severe traumatic brain injury. XIII Antiseizure prophylaxis. J Neurotrauma. 2006;24:S83-6.

31. Sundararajan $\mathrm{K}$, et al. Anti-seizure prophylaxis in critically ill patients with traumatic brain injury in an intensive care unit. Anaesth Intensive Care. 2015;43(5):646-51.

32. Cranley MR, Craner M, McGilloway E. Antiepileptic prophylaxis following severe traumatic brain injury within a military cohort. J R Army Med Corps. 2015;162:109-14.

33. Cotton BA, et al. Cost-utility analysis of levetiracetam and phenytoin for posttraumatic seizure prophylaxis. J Trauma Acute Care Surg. 2011;71(2): 375-9.

34. Jones $\mathrm{KE}$, et al. Levetiracetam versus phenytoin for seizure prophylaxis in severe traumatic brain injury. Neurosurg Focus. 2008;25(4):E3.

35. Zangbar B, et al. Levetiracetam prophylaxis for post-traumatic brain injury seizures is ineffective: a propensity score analysis. World I Surg. 2016;40(11): 2667-72.

36. Szaflarski JP, et al. Prospective, randomized, single-blinded comparative trial of intravenous levetiracetam versus phenytoin for seizure prophylaxis. Neurocrit Care. 2010;12(2):165-72.

37. Temkin NR, et al. Valproate therapy for prevention of posttraumatic seizures: a randomized trial. J Neurosurg. 1999;91(4):593-600.

38. Bladin CF, et al. Seizures after stroke: a prospective multicenter study. Arch Neurol. 2000;57(11):1617-22.

39. Szaflarski JP, et al. Incidence of seizures in the acute phase of stroke: a population-based study. Epilepsia. 2008;49(6):974-81.

40. Bryndziar T, et al. Seizures following ischemic stroke: frequency of occurrence and impact on outcome in a long-term population-based study. J Stroke Cerebrovasc Dis. 2016;25(1):150-6. 
41. Hamidou B, et al. Prognostic value of early epileptic seizures on mortality and functional disability in acute stroke: the Dijon Stroke Registry (19852010). J Neurol. 2013;260(4):1043-51.

42. Cleary P, Shorvon S, Tallis R. Late-onset seizures as a predictor of subsequent stroke. Lancet. 2004;363(9416):1184-6.

43. Jauch EC, et al. Guidelines for the early management of patients with acute ischemic stroke. Stroke. 2013;44(3):870-947.

44. Alvarez $\mathrm{V}$, et al. Acute seizures in acute ischemic stroke: does thrombolysis have a role to play? J Neurol. 2013;260(1):55-61.

45. Reith J, et al. Seizures in acute stroke: predictors and prognostic significance. The Copenhagen Stroke Study. 1997;28(8):1585-9.

46. Lamy C, et al. Early and late seizures after cryptogenic ischemic stroke in young adults. Neurology. 2003;60(3):400-4.

47. Beghi $E$, et al. Incidence and predictors of acute symptomatic seizures after stroke. Neurology. 2011;77(20):1785-93.

48. Rumbach $L$, et al. Status epilepticus in stroke: report on a hospital-based stroke cohort. Neurology. 2000;54(2):350.

49. Guo J, et al. Statin treatment reduces the risk of poststroke seizures. Neurology. 2015;85(8):701-7.

50. Siniscalchi A, Mintzer S. Statins for poststroke seizures: the first antiepileptogenic agent? Neurology. 2015;85:661-2.

51. Lahti A-M, et al. Poststroke epilepsy in long-term survivors of primary intracerebral hemorrhage. Neurology. 2017:88(23):2169-75.

52. Giroud M, et al. Early seizures after acute stroke: a study of 1,640 cases. Epilepsia. 1994;35(5):959-64.

53. Vespa PM, et al. Acute seizures after intracerebral hemorrhage: a factor in progressive midline shift and outcome. Neurology. 2003;60(9):1441-6.

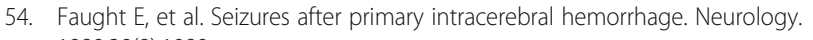
1989;39(8):1089.

55. Tatu L, et al. Primary intracerebral hemorrhages in the Besancon stroke registry. Eur Neurol. 2000;43(4):209-14.

56. Claassen J, et al. Electrographic seizures and periodic discharges after intracerebral hemorrhage. Neurology. 2007;69(13):1356-65.

57. Garrett MC, et al. Predictors of seizure onset after intracerebral hemorrhage and the role of long-term antiepileptic therapy. J Crit Care. 2009;24(3):335-9.

58. Morgenstern LB, et al. Guidelines for the management of spontaneous intracerebral hemorrhage. A guideline for healthcare professionals from the American Heart Association/American Stroke Association. Stroke. 2010;41:2108-29.

59. Naidech AM, et al. Evolving use of seizure medications after intracerebral hemorrhage: a multicenter study. Neurology. 2017;88(1):52-6.

60. Naidech AM, et al. Anticonvulsant use and outcomes after intracerebral hemorrhage. Stroke. 2009;40(12):3810-5

61. Messé SR, et al. Prophylactic antiepileptic drug use is associated with poor outcome following ICH. Neurocrit Care. 2009;11(1):38-44.

62. Gilmore EJ, et al. Review of the utility of prophylactic anticonvulsant use in critically ill patients with intracerebral hemorrhage. Stroke. 2016; 47(10):2666-72.

63. Sheth $\mathrm{KN}$, et al. Prophylactic antiepileptic drug use and outcome in the ethnic/racial variations of intracerebral hemorrhage study. Stroke. 2015; 46(12):3532-5

64. Zandieh A, et al. Prophylactic use of antiepileptic drugs in patients with spontaneous intracerebral hemorrhage. J Stroke Cerebrovasc Dis. 2016;25(9): 2159-66.

65. Maciel CB, Gilmore EJ. Seizures and epileptiform patterns in SAH and their relation to outcomes. J Clin Neurophysiol. 2016;33(3):183-95.

66. Panczykowski D, et al. Prophylactic antiepileptics and seizure incidence following subarachnoid hemorrhage. Stroke. 2016;47(7):1754-60.

67. Connolly ES, et al. Guidelines for the management of aneurysmal subarachnoid hemorrhage. Stroke. 2012;43:1711-37.

68. Diringer MN, et al. Critical care management of patients following aneurysmal subarachnoid hemorrhage: recommendations from the Neurocritical Care Society's Multidisciplinary Consensus Conference. Neurocrit Care. 2011;15(2):211.

69. Bauer $\mathrm{R}$, et al. Treatment of epileptic seizures in brain tumors: a critical review. Neurosurg Rev. 2014;37(3):381-8.

70. Garbossa D, et al. A retrospective two-center study of antiepileptic prophylaxis in patients with surgically treated high-grade gliomas. Neurol India. 2013;61(2):131.

71. Kruer RM, et al. Changing trends in the use of seizure prophylaxis after traumatic brain injury: a shift from phenytoin to levetiracetam. J Crit Care. 2013;28(5):883. e9-883. e13
72. Zafar SN, et al. Phenytoin versus leviteracetam for seizure prophylaxis after brain injury - a meta analysis. BMC Neurol. 2012;12(1):30.

73. Glantz M, et al. Practice parameter: anticonvulsant prophylaxis in patients with newly diagnosed brain tumors. Report of the Quality Standards Subcommittee of the American Academy of Neurology. Neurology. 2000; 54(10):1886-93.

74. Soffietti R, et al. Guidelines on management of low-grade gliomas: report of an EFNS-EANO Task Force. Eur J Neurol. 2010;17(9):1124-33.

75. Wychowski T, et al. Considerations in prophylaxis for tumor-associated epilepsy: prevention of status epilepticus and tolerability of newer generation AEDs. Clin Neurol Neurosurg. 2013;115(11):2365-9.

76. Masuhr F, et al. Risk and predictors of early epileptic seizures in acute cerebral venous and sinus thrombosis. Eur J Neurol. 2006;13(8):852-6.

77. Ferro J, et al. Seizures in cerebral vein and dural sinus thrombosis. Cerebrovasc Dis. 2003;15:78-83.

78. Ferro JM, et al. Early seizures in cerebral vein and dural sinus thrombosis. Stroke. 2008;39(4):1152-8.

79. Mahale $R$, et al. Acute seizures in cerebral venous sinus thrombosis: what predicts it? Epilepsy Res. 2016;123:1-5.

80. Davoudi V, Saadatnia M. Risk factors for remote seizure development in patients with cerebral vein and dural sinus thrombosis. Seizure. 2014; 23(2):135-9.

81. Kalita J, Chandra S, Misra UK. Significance of seizure in cerebral venous sinus thrombosis. Seizure. 2012;21(8):639-42.

82. Claassen J, et al. Detection of electrographic seizures with continuous EEG monitoring in critically ill patients. Neurology. 2004;62(10):1743-8.

83. Westover MB, et al. The probability of seizures during EEG monitoring in critically ill adults. Clin Neurophysiol. 2015;126(3):463-71.

84. Bauer G, Trinka E. Nonconvulsive status epilepticus and coma. Epilepsia. 2010;51(2):177-90

85. Sivaraju A, Gilmore EJ. Understanding and managing the ictal-interictal continuum in neurocritical care. Curr Treat Options Neurol. 2016;18(2):8.

86. Rodríguez V, Rodden MF, LaRoche SM. Ictal-interictal continuum: a proposed treatment algorithm. Clin Neurophysiol. 2016;127(4):2056-64.

87. Costello DJ, Cole AJ. Treatment of acute seizures and status epilepticus. J Intensive Care Med. 2007;22(6):319-47.

88. Billington M, Kandalaft OR, Aisiku IP. Adult status epilepticus: a review of the prehospital and emergency department management. J Clin Med. 2016;5(9):74

89. Treiman DM, et al. A comparison of four treatments for generalized convulsive status epilepticus. N Engl J Med. 1998;339(12):792-8.

90. Silbergleit $R$, et al. Intramuscular versus intravenous therapy for prehospital status epilepticus. N Engl J Med. 2012;366(7):591-600.

91. McIntyre J, et al. Safety and efficacy of buccal midazolam versus rectal diazepam for emergency treatment of seizures in children: a randomised controlled trial. Lancet. 2005;366(9481):205-10.

92. Misra U, Kalita J, Maurya P. Levetiracetam versus lorazepam in status epilepticus: a randomized, open labeled pilot study. J Neurol. 2012; 259(4):645-8.

93. Navarro V, et al. Prehospital treatment with levetiracetam plus clonazepam or placebo plus clonazepam in status epilepticus (SAMUKeppra): a randomised, double-blind, phase 3 trial. Lancet Neurol. 2016;15(1):47-55.

94. Brophy G, et al. Neurocritical Care Society Status Epilepticus Guideline Neurocrit Care Writing Committee. Guidelines for the evaluation and management of status epilepticus. Neurocrit Care. 2012;17:3-23.

95. Misra U, Kalita J, Patel R. Sodium valproate vs phenytoin in status epilepticus: a pilot study. Neurology. 2006;67(2):340-2.

96. Höfler J, Trinka E. Lacosamide as a new treatment option in status epilepticus. Epilepsia. 2013;54(3):393-404.

97. Strzelczyk A, et al. Treatment of refractory and super-refractory status epilepticus with brivaracetam: A cohort study from two German university hospitals. Epilepsy Behav. 2017;70:177-81.

98. Hirsch L, Gaspard N. Status epilepticus CONTINUUM: lifelong learning in neurology. Continuum. 2013;19(3, Epilepsy):767-94.

99. DeLorenzo R, et al. Persistent nonconvulsive status epilepticus after the control of convulsive status epilepticus. Epilepsia. 1998;39(8):833-40.

100. Rossetti AO, Lowenstein DH. Management of refractory status epilepticus in adults: still more questions than answers. Lancet Neurol. 2011;10(10):922-30.

101. Miller AD, et al. Epileptogenic potential of carbapenem agents: mechanism of action, seizure rates, and clinical considerations. Pharmacotherapy. 2011; 31(4):408-23. 
102. Pisani F, et al. Effects of psychotropic drugs on seizure threshold. Drug Saf. 2002;25(2):91-110.

103. Asconape JJ. Use of antiepileptic drugs in hepatic and renal disease. In: Miller J, Ferro JM, editors. Handbook of Clinical Neurology. 2014;119:417-32.

104. Mahmoud SH. Antiepileptic drug removal by continuous renal replacement therapy: a review of the literature. Clin Drug Investig. 2017;37(1):7-23.

105. Porto I, John EG, Heilliczer J. Removal of phenobarbital during continuous cycling peritoneal dialysis in a child. Pharmacotherapy. 1997;17(4):832-5.

106. Palmer BF. Effectiveness of hemodialysis in the extracorporeal therapy of phenobarbital overdose. Am J Kidney Dis. 2000;36(3):640-3.

107. Schetz M, et al. Pharmacokinetics of continuous renal replacement therapy. Intensive Care Med. 1995;21(7):612-20.

108. Reetze-Bonorden P, Bohler J, Keller E. Drug dosage in patients during continuous renal replacement therapy. Pharmacokinetic and therapeutic considerations. Clin Pharmacokinet. 1993:24(5):362-79.

109. Silberstein LE, Shaw LM. Effect of plasma exchange on phenytoin plasma concentration. Ther Drug Monit. 1986;8(2):172-6.

110. Ibrahim RB, et al. Drug removal by plasmapheresis: an evidence-based review. Pharmacotherapy. 2007;27(11):1529-49.

111. Elliott ES, Buck ML. Phenobarbital dosing and pharmacokinetics in a neonate receiving extracorporeal membrane oxygenation. Ann Pharmacother. 1999;33(4):419-22.

112. Shekar $K$, et al. Pharmacokinetic changes in patients receiving extracorporeal membrane oxygenation. J Crit Care. 2012;27(6):741. e9-18

113. Shekar $\mathrm{K}$, et al. Protein-bound drugs are prone to sequestration in the extracorporeal membrane oxygenation circuit: results from an ex vivo study. Crit Care. 2015;19:164.

114. Nei SD, et al. Levetiracetam pharmacokinetics in a patient receiving continuous venovenous hemofiltration and venoarterial extracorporea membrane oxygenation. Pharmacotherapy. 2015;35(8):e127-30.

115. Patsalos PN. Drug interactions with the newer antiepileptic drugs (AEDs) - part 2: pharmacokinetic and pharmacodynamic interactions between AEDs and drugs used to treat non-epilepsy disorders. Clinical pharmacokinetics. 2013;52(12):1045-1061.

116. Patsalos PN, Perucca E. Clinically important drug interactions in epilepsy: general features and interactions between antiepileptic drugs. The Lancet Neurology. 2003;2(6):347-356.

117. Sancho J, Serratosa J. Antiepileptic drug interactions. The neurologist. 2008; 14(6):S55-S65.

118. Schmidt D, Schachter SC. Drug treatment of epilepsy in adults. Bmj. 2014; 348:g254.

119. Perucca E. Clinically relevant drug interactions with antiepileptic drugs. British journal of clinical pharmacology. 2006;61(3):246-255.

120. French J, et al. Efficacy and tolerability of the new antiepileptic drugs I: Treatment of new onset epilepsy Report of the Therapeutics and Technology Assessment Subcommittee and Quality Standards Subcommittee of the American Academy of Neurology and the American Epilepsy Society. Neurology. 2004;62(8):1252-1260.

121. Food U and D Administration. VIMPAT ${ }^{\oplus}$ (lacosamide) Prescribing Information. Accessed July, 2017

122. Ingelheim B. Pradaxa (dabigatran) package insert. Ridgefield, CT. 2012.

123. Healthcare B. Xarelto (rivaroxaban) package insert. 2012

124. Squibb B.-M. Eliquis (apixaban) package insert. 2015.

125. Nappi JM. Warfarin and phenytoin interaction. Ann Intern Med. 1979;90(5):852.

126. Levine M, Sheppard I. Biphasic interaction of phenytoin with warfarin. Clin Pharm. 1984;3(2):200-3.

127. Food U and D. Administration, Cordarone (Amiodarone HCL) Tablets: Package Insert. US Food and Drug Administration, Maryland. 2010

128. Macphee GA, et al. Verapamil potentiates carbamazepine neurotoxicity: a clinically important inhibitory interaction. The Lancet. 1986;327(8483):700-703.

129. Maoz $\mathrm{E}_{\text {, et }}$ al. Carbamazepine neurotoxic reaction after administration of diltiazem. Archives of internal medicine. 1992;152(12):2503-2504.

130. Bahls FH, Ozuna J, Ritchie DE. Interactions between calcium channel blockers and the anticonvulsants carbamazepine and phenytoin. Neurology. 1991;41(5):740-742.

131. I Johannessen, S. and C. Johannessen Landmark, Antiepileptic drug interactionsprinciples and clinical implications. Current neuropharmacology. 2010;8(3):254-267.

132. Park MK, et al. Reduced valproic acid serum concentrations due to drug interactions with carbapenem antibiotics: overview of 6 cases. Therapeutic drug monitoring. 2012;34(5):599-603. 